\title{
UMA ANÁLISE DA QUESTÃO DA VIOLÊNCIA CONTRA A MULHER E OS EFEITOS DAS POLÍTICAS PÚBLICAS SOBRE O NÚMERO DE DENÚNCIAS DE ESTUPRO NO ESTADO DO RIO DE JANEIRO
}

\author{
ANALYSIS OF VIOLENCE AGAINST WOMEN AND THE IMPACT OF PUBLIC POLICIES ON \\ THE NUMBER OF RAPE REPORTS IN THE STATE OF RIO DE JANEIRO, BRAZIL
}

Resumo: Diante do aumento da percepção da dimensão do problema da violência contra a mulher, percebe-se a importância de averiguar se as leis vigentes e as políticas públicas implantadas para combater esse tipo de violência estão obtendo eficácia, a fim de que se possa aprimorar as políticas existentes e, ainda, auxiliar na criação de novas maneiras de enfrentamento desse tipo de violência. Desde a década de 90, o assunto tem sido abordado como um problema amplo e complexo - visto que afeta todas as mulheres da sociedade, sem levar em conta classe social, raça, idade, local -, o que consolida a necessidade de se buscar entendê-lo a partir de uma dimensão social. Dessa forma, este trabalho tem o objetivo de analisar a variação das denúncias dos casos de estupro registrados no estado do Rio de Janeiro, em função da implementação das políticas públicas, a fim de avaliar as possíveis alterações no cenário estadual. 0 trabalho foi realizado por meio de um levantamento de dados a partir do Dossiê Mulher Instituto de Segurança Pública - Governo do Estado do Rio de Janeiro, que compreende informações do período de 2003 até o primeiro semestre do ano de 2019. Percebeuse, a partir do estudo, o aumento do número de denúncias de violência contra a mulher no estado do Rio de Janeiro, indicando que a sociedade está reagindo e a luta social está tendo mais visibilidade e efeito, o que representa também a saída da esfera privada para a esfera pública.

Palavras-Chave: violência contra a mulher. Gênero. Direitos humanos. Políticas públicas. Estupro.

Matheus Machado Orioli

Mestrando UCAM - Planejamento Regional e Gestão da Cidade.

Priscila Kelly Pedrosa Corrêa

Mestranda UCAM - Planejamento Regional e Gestão da Cidade. Pesquisadora GPIDMR-Itep-UENF-UNIFLU.
Abstract: Faced with the increasing perception of the dimension of the issue of violence against women, it is perceived the importance of ascertaining whether the laws in force and the public policies implemented to fight this violence are becoming effective, so that existing policies can be improved and help in the creation of new ways to confront this type of violence. Accordingly, the purpose of this study is to analyze the variation in the number of reports of rape cases registered in the state of Rio de Janeiro, Brazil, in accordance with the implementation of public policies, with a view to evaluating possible changes in the state scenario. The study was conducted by means of a data survey from the Dossiê Mulher - Instituto de Segurança Pública - Governo do Estado do Rio de Janeiro, which includes information from 2003 to the first half of 2019. From the study, the increase in the number of reports of violence against women in the state of Rio de Janeiro was perceived, suggesting that society is responding and the social struggle is having more visibility and effect, which also represents the way out from the private to the public domain.

Keywords: Violence against women. Gender. Human rights. Public policies. Rape.

Silvana Coutinho de Andrade Ribeiro

Mestranda UCAM - Planejamento Regional e Gestão da Cidade.

Ludmila Gonçalves da Matta

Prof. Doutora, em Sociologia Política. Professora do Curso da Mestrado UCAM - Planejamento Regional e Gestão de Cidade 


\section{Introdução}

Diante do aumento dos índices de violência contra a mulher, cria-se a necessidade de averiguar se as leis vigentes e as políticas públicas implantadas para combater esse tipo de violência estão obtendo eficácia - ou seja, se estão realmente sendo capazes de fazer com que as vítimas tenham consciência de seus direitos e denunciem o agressor, a fim de que este seja punido, reduzindo, assim, o expressivo número de vítimas retratado nos dados estatísticos -, com o objetivo de aprimorar as políticas existentes e, ainda, auxiliar na criação de novas maneiras de enfrentamento desse tipo de violência.

Desde a década de 90, o assunto tem sido abordado como um problema amplo e complexo - visto que afeta todas as mulheres da sociedade, sem levar em conta classe social, raça, idade, local -, o que consolida a necessidade de entendê-lo a partir de uma dimensão social, buscando conceitos e fundamentos em referencial teórico-metodológico, para amparar as práticas de combate a essa mazela social.

0 objetivo deste trabalho é analisar a variação das denúncias dos casos de estupro registrados no estado do Rio de Janeiro, em função da implementação das políticas públicas, a fim de avaliar as possíveis alterações no cenário estadual.

0 recorte de estudo se limita à análise de dados em escala estadual, atentando para as condições do combate à violência contra a mulher, no que concerne os números de denúncias dos casos de estupro verificados, considerando todas as alterações feitas pela legislação no decorrer dos anos.

Na primeira parte do trabalho, são expostos alguns aspectos e conceitos da violência contra a mulher, intentando uma maior clareza quanto às dimensões dessa conjuntura.

Na segunda etapa, são apresentados e analisados dados acerca da violência contra a mulher no estado do Rio de Janeiro, para que se possa compreender o panorama geral no que tange à quantificação e (quando possível) tipificação dos casos registrados, no período que compreende do ano 2003 até o primeiro semestre do ano de 2019, com dados extraídos do Dossiê Mulher - Instituto de Segurança Pública - Governo do Estado do Rio de Janeiro do período em questão.

\section{Aspectos e considerações da violência contra a mulher}

A questão do combate à violência contra a mulher é percebida por diversos autores como um processo histórico de um movimento social de luta por direitos. Segundo Saffioti (2004, p. 76):

\begin{abstract}
Já desde a Revolução Francesa os direitos humanos foram pensados no masculino: Declaração Universal dos Direitos do Homem e do Cidadão. Por haver escrito a versão feminina dos direitos humanos (Declaração Universal dos Direitos da Mulher e da Cidadã), Olympe de Gouges foi sentenciada à morte na guilhotina, em 1792.
\end{abstract}

\section{A QUALIDADE DE ENSINO QUE VOCE JÁ GOWHECE.}

UNIVERSIDADE

CANDIDO

MENDES
INSCREVA-SE AGORA!

口 PRESENCIAL

口 SEMIPRESENCIAL

口 EAD

www.ucam-campos.br

22 2726-2400 
Ao se observar o panorama histórico desse movimento, é possível constatar uma mudança na percepção desses direitos. Tradicionalmente, os direitos de cidadão, garantidos como direitos naturais, eram restritos a certos grupos. Com o passar do tempo, a conscientização e mudança de juízo sobre determinados direitos, por uma parcela significativa da população, impulsionaram esses movimentos que, por muitas vezes, são combatidos com violência - direta ou indireta.

Estruturas de dominação não se transformam meramente através legislação. Esta é importante, na medida em que permite a qualquer cidadão prejudicado pelas práticas discriminatórias recorrer à justiça. Todavia, enquanto perdurarem discriminações legitimadas pela ideologia dominante, especialmente contra a mulher, os próprios agentes da justiça tenderão a interpretar as ocorrências que devem julgar à luz do sistema de ideias justificador do presente estado de coisas.

0 poder está concentrado em mãos masculinas há milênios. E os homens temem perder privilégios que asseguram sua supremacia sobre as mulheres. (SAFFIOTI, 1987, p.15-16)

A violência contra a mulher está, de certo modo, historicamente enraizada na sociedade, visto que está diretamente relacionada à imagem de submissão e inferioridade feminina, procedente dessa histórica negligência de direitos, supressão do poder de opinião e falta de representatividade.

É possível sustentar, ainda, que todo esse processo histórico acaba por legitimar uma produção social fundamentada na opressão machista e patriarcal, de modo a naturalizar a violência contra a mulher e a torná-la corriqueira.

A compreensão deste processo poderá promover enormes avanços na caminhada da conscientização quer de mulheres, quer de homens, a fim de que se possa desmistificar o pretenso caráter natural das discriminações praticadas contra os elementos femininos.

Do exposto pode-se facilmente concluir que a inferioridade feminina é exclusivamente social. (SAFFIOTI, 1987, p.15).
Chauí (2011, p. 381 e 382) reitera que:

Há, no Brasil, um mito poderoso, o da não-violência brasileira, isto é, a imagem de um povo generoso, alegre, sensual, solidário, que desconhece o racismo, o sexismo, o machismo, que respeita as dificuldades étnicas, religiosas e políticas, não discrimina as pessoas por suas escolhas sexuais, etc. [...] 0 mito da não-violência permanece porque, graças a ele, admite-se a existência de fato da violência e pode-se, ao mesmo tempo, fabricar explicações para denegá-la no instante mesmo em que é admitida

Nessa perspectiva, Guimarães e Pedroza (2015, p. 261) entendem:

o quanto a sociedade brasileira é autoritária e estruturada em relações de mando e obediência, sustentadas com base em padrões patriarcais e machistas. Essa invisibilidade da violência estruturante de nossa realidade alia-se às desigualdades de gênero e, dessa maneira, ao negar direitos às mulheres e atribuir força e autoritarismo aos homens, acaba-se por legitimar e naturalizar muitas das violências sofridas por elas. Violências que são demarcadas na intersubjetividade entre masculinidade(s) e feminilidade(s). Violências que surgem nesse encontro com a alteridade e na própria negação da mesma.

Na questão da violência de gênero, salienta Bandeira (2014, p. 457):

Os estudos feministas sobre a violência de gênero consideram, em especial, como um dos pilares da violência contra a mulher o patriarcado e, de modo correlato, a posição de dominação simbólica masculina. Contudo, reconhecem que há outros elementos que compõem a dinâmica da violência.

Ainda sobre a violência de gênero, Bandeira (2014, p. 458) aborda dois fatores como as armadilhas e táticas utilizadas nesse comportamento:

o que se poderia chamar das armadilhas e táticas do poder patriarcal, na medida em que a existência das mulheres é carregada de sentidos: ser esposa, mãe, filha, cuidadora, entre os compromissos de ser fiel, companheira, amiga, boa mãe, dentre outros. 0 registro do patriarcado é demarcado na carne e não é sutil, porém, mais forte é a demarcação simbólica, que quando quebrada, responde com a morte, uma vez que não podemos romper como reprodutoras da ordem social e biológica que nos foi imposta.

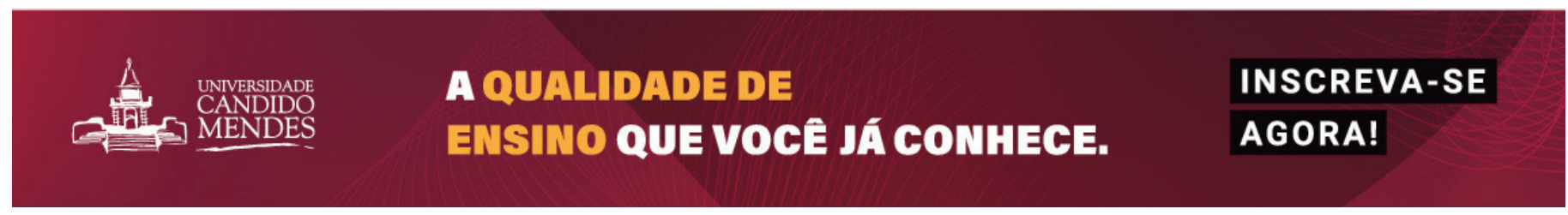


A percepção da questão da violência contra a mulher como algo a ser enfrentado vem, ao longo dos anos, se diversificando e intensificando, vindo a ser considerada, a partir da década de 1990, problema de saúde pública, gênero e direitos humanos. Desde então, os estudos e estatísticas apontam que a violência contra a mulher não se restringe à violência física, mas abrange um conjunto de transgressões, que inclui violência doméstica, sexual, psicológica, patrimonial, moral, institucional, tráfico de mulheres, exploração sexual de mulheres, exploração sexual comercial de mulheres, adolescentes/jovens, assédio sexual, assédio moral e cárcere privado.

A "Convenção de Belém do Pará" [Convenção Interamericana para Prevenir, Punir e Erradicar a Violência contra a Mulher, adotada pela Organização dos Estados Americanos (OEA)] - realizada em Belém do Pará, Brasil, em 9 de junho de 1994 - traz, em seu primeiro capítulo, artigo primeiro, que: "deve-se entender por violência contra a mulher qualquer ação ou conduta, baseada no gênero, que cause morte, dano ou sofrimento físico, sexual ou psicológico à mulher, tanto no âmbito público como no privado" (Convenção de Belém do Pará, 1994, p.2). 0 texto da convenção sustenta, ainda, que violência contra a mulher constitui violação dos direitos humanos.

A Lei no 11.340, conhecida como Lei Maria da Penha, instituída em 7 de agosto de 2006 com o desígnio de tratar exclusivamente de casos de violência contra a mulher, foi um marco no combate à violência contra a mulher - antes da publicação da lei, casos de agressão, por exemplo, eram enquadrados no juizado de pequenas causas, tinham penas muito baixas e acabavam sendo convertidos em penas alternativas, como doação de cestas básicas. Em 13 de maio de 2019, a lei ganha mais uma melhoria, com a publicação da Lei $n^{0}$ 13.827, que altera o texto da Lei Maria da Penha, incluindo autorizar, em hipóteses específicas, a aplicação de medida protetiva de urgência, podendo o agressor ser imediatamente afastado do lar no caso de violência doméstica.

A criação das Delegacias Especializadas de Atendimento à Mulher (DEAM) há 35 anos, foi uma conquista muito importante, visto que, em muitos casos, havia, até então, uma resistência pessoal na hora de fazer a denúncia, uma vez que algumas mulheres eram atendidas por indivíduos que, ao invés de registrarem a denúncia da violência, acabavam por cometer outra contra a vítima.

Nessas delegacias (DEAMs) a finalidade não é apenas punir os agressores, mas também proporcionar amparo e orien- tação às vítimas sobre seus direitos e estimular denúncias das agressões, além de fazer estudos para a identificação do perfil de agressores (BREDER, 2018). Hoje são 14 delegacias especializadas nesse atendimento no estado do Rio de Janeiro segundo a Polícia Civil do estado.

Segundo Bandeira (2014, p. 452):

A característica marcante que ancora a existência da Deam é a construção de um ordenamento de valores diferenciados, que possibilitem a escuta e o olhar distintos em relação ao parâmetro masculino de compreensão sobre a violência. Ou seja, estas delegacias devem ter seus quadros funcionais compostos por delegadas e agentes policiais mulheres capacitadas em relação às especificidades que caracterizam a violência contra a mulher, assim como a mais ampla compreensão do(s) contexto(s) em que ocorre.

Apesar dos esforços nesse combate com instrumentos legais, políticas públicas e campanhas de conscientização, o número de vítimas que não realizam denúncias ainda é muito significativo, facilitando sucessivos episódios de violência, e, à medida que a violência - seja ela de qualquer natureza - ocorre, de forma recorrente e gradativa, tende a se mostrar cada vez mais pujante, muitas vezes levando à morte.

"Femicídio" ou "feminicídio" são expressões utilizadas para denominar as mortes violentas de mulheres em razão de gênero, ou seja, que tenham sido motivadas por sua condição de muIher. Segundo Alicia Bárcena, secretária-executiva da Comissão Econômica para a América Latina e o Caribe (CEPAL):

0 feminicídio é a expressão mais extrema da violência contra as mulheres. Nem a tipificação do crime nem sua visibilização estatística foram suficientes para erradicar esse flagelo que nos alarma e horroriza a cada dia. (ONU, 2018, p. 2).

Marixa Fabiane Lopes Rodrigues, juíza de Direito do Tribunal de Justiça de Minas Gerais, reitera que:

A subjugação máxima da mulher por meio de seu extermínio tem raízes históricas na desigualdade de gênero e sempre foi invisibilizada e, por consequência, tolerada pela sociedade. A mulher sempre foi tratada como uma coisa que o homem podia usar, gozar e dispor. (PRAD0, 2016). 
No Brasil, o crime de feminicídio foi reconhecido legalmente após a publicação da Lei no 13.104/2015, que fez alterações no art. 121 do Código Penal (Decreto-Lei n 2.848/1940), onde incluiu o feminicídio como circunstância de qualificação do crime de homicídio.

Dentre os crimes de violência sexual, o estupro é um dos mais antigos praticados, pois os agressores ocupam os mais variados e inesperados locais, conforme menciona Souza (2017, p. 11):

Relatos sobre casos de estupro acontecem nos mais variados ambientes, desde o temido beco escuro onde todas as mães instruem suas filhas a não transitarem, até mesmo 0 grande número de incidências ocorridas dentro da 'pretensa casa segura' da vítima.

Como uso de poder e submissão, como salienta Saffioti (1987, p.18):

0 caso extremo do uso do poder nas relações homem-mulher pode ser caracterizado pelo estupro. Contrariando a vontade da mulher, o homem mantém com ela relações sexuais, provando, assim, sua capacidade de submeter a outra parte, ou seja, aquela que, segundo a ideologia dominante, não tem direito de desejar, não tem direito de escolha.

Além disso, o crime de estupro foi o que mais sofreu modificação em sua tipificação com o passar dos anos. Verificou-se que a questão do estupro não está condicionada apenas à penetração, pois a atividade sexual humana não tem como finalidade única a reprodução. Atualmente, a sexualidade é aceita não apenas para fins de procriação, mas também para socialização, satisfação de prazeres, estabelecimento de relações amorosas, relações sociais, recreação, entre outros. No entanto, para a realização de seu desejo sexual, o agressor pode se manifestar de várias formas, porém nenhuma delas respeita a vontade e a dignidade da vítima. (SOUZA, 2017).

Outra modificação importante a ser mencionada sobre esse tipo de crime foi a criação da Lei $n^{0} .12 .015 / 09$, de 7 de agosto de 2009, que passou a incluir o homem como possível vítima de estupro, uma vez que, antes, estava desamparado pela legislação. No entanto, o crime de violência sexual ainda é uma realidade que assombra muito mais o universo feminino.

\section{Considerações metodológicas}

Este estudo foi desenvolvido por meio de pesquisa descritiva e exploratória, que objetiva esclarecer ideias, sendo desenvolvida de modo a proporcionar maior familiaridade com o problema investigado, a fim de explicitá-lo melhor e construir uma visão geral sobre determinado fato ou situação, envolvendo levantamento bibliográfico e pesquisa na base de dados apresentada no Dossiê Mulher - Instituto de Segurança Pública - Governo do Estado do Rio de Janeiro.

De acordo com Gil (2010, p. 44), as pesquisas descritivas são úteis para encontrar e descrever características de certa população, sendo "inúmeros os estudos que podem ser classificados sob este título e uma de suas características mais significativas está na utilização de técnicas padronizadas de coletas de dados".

A pesquisa exploratória é utilizada quando o pesquisador se depara com temas pouco estudados, o que torna difícil a formulação de hipóteses, assumindo, geralmente, as formas de pesquisas bibliográficas e estudos de caso (GIL, 2010).

O Dossiê Mulher é uma publicação anual da Secretaria de Segurança Pública do estado do Rio de Janeiro, e traz informações relativas à violência contra a mulher. 0 relatório aborda os principais crimes que milhares de mulheres sofrem cotidianamente, como a lesão corporal dolosa, a ameaça, o atentado violento ao pudor, o estupro, o homicídio doloso e a violência doméstica. Para essa pesquisa, foram analisadas as publicações do Dossiê no período de 2003 a 2019.

\section{Resultados e Discussão}

Nesta seção, apresentamos o levantamento sobre a situação da violência contra a mulher a partir da descrição e análise dos dados sobre os casos de estupro registrados no estado do Rio de Janeiro. Buscamos verificar a correlação entre a implementação de políticas públicas voltadas para a proteção da mulher - e a incidência dos casos de violência.

De acordo com as informações extraídas do Dossiê Mulher, houve um crescimento de 28.731 para 31.608 no número de registros de violência contra a mulher no estado entre os anos de 2003 e 2004, o que indica que, a partir do aumento das denúncias, a sociedade já estava reagindo para combater a banalização dos casos, isso mesmo antes da Lei n 11.340.

0 ano de 2005 registrou uma média mensal de 118 denúncias, o que representa uma média diária de quatro vítimas, um total de 1.416 no ano. Com relação ao ano de 2004, apresentou aumento 20,6\%. 
Em 2006, foi registrada média mensal de 107 denúncias de estupro no estado, representando, nos registros, uma média de quatro vítimas por dia. Com relação ao ano anterior, 2006 apresentou uma redução de 138 registros, ou ainda 9,7\% a menos do que em 2005. Percebe-se que essa redução aconteceu no ano da criação da Lei no 11.340 de 7 de agosto de 2006 (Lei Maria da Penha). Pode-se inferir, como hipótese, que houve, de certa forma, uma inibição do comportamento do agressor, visto que, a partir de então, passou a existir um mecanismo para coibir esse tipo de violência. Por outro lado, pode-se inferir a hipótese de que as vítimas também se inibiram em denunciá-los em razão da legislação ter se tornado mais rigorosa com os agressores, não podendo mais serem punidos, como de costume, com penas alternativas como o pagamento de cestas básicas. Com a lei, ficou decretada pena de detenção, que, atualmente, pode chegar a até três anos. E nos casos onde o único provento da casa vem do agressor, as vítimas se veem coagidas e condicionam sua decisão, muitas vezes, a questões associadas ao campo financeiro e afetivo.

No entanto, no ano de 2007, houve 1.376 registros de denúncias de estupro. Este número significa um aumento de 7,7\%, ou de 98 de- núncias de vítimas, em relação ao ano de 2006, e representa uma média mensal de 115 vítimas que fizeram a denúncia, alcançando, aproximadamente, quatro vítimas por dia. A cada 100 mil habitantes, 8,7 mulheres foram vitimizadas no ano de 2007. Percebe-se que, no ano seguinte, com a criação dessa lei, as denúncias aumentaram. Isso demonstra uma certa efetividade da política pública, uma vez que passou a existir uma legislação específica voltada para tratar desse tipo de crime dentro do contexto de violência contra a mulher. Observa-se que houve uma maior conscientização por parte da sociedade, o que possibilitou que as vítimas fossem encorajadas, por pessoas próximas ou por familiares, a denunciarem o crime, e que também conseguissem medida protetiva, proporcionando maior segurança.

Vale ressaltar que, com os anos, o crime de estupro passou a ser enquadrado como um dos tipos de violência sexual, e outros tipos de violência foram sendo reconhecidos como crime, tais como tentativa de estupro, assédio sexual, importunação ofensiva ao pudor e ato obsceno.

\section{Gráfico 1 - Percentual anual dos registros em DEAM - 1999-2005}

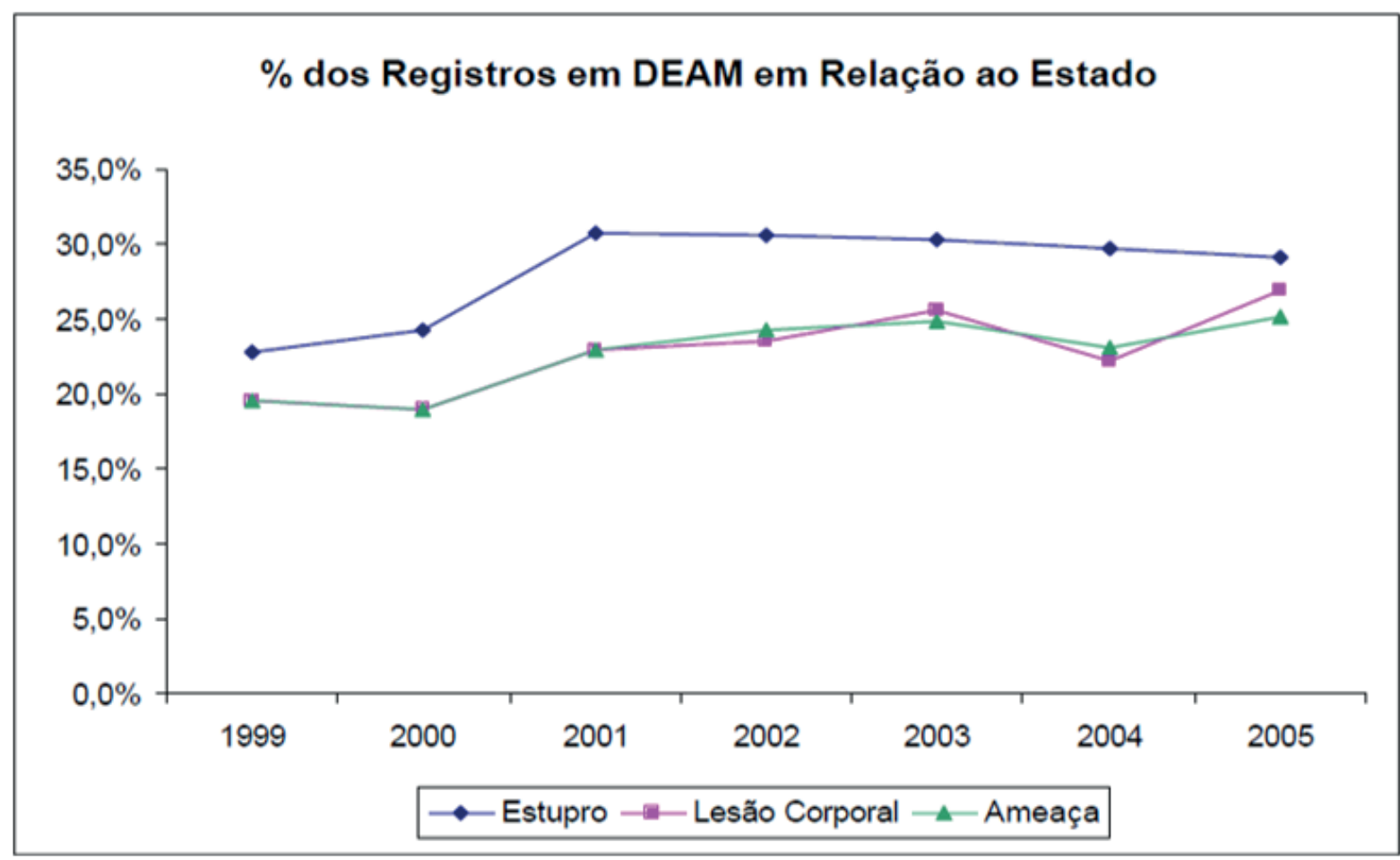

Fonte: Dossiê Mulher - Instituto de Segurança Pública - Governo do Estado do Rio de Janeiro, 2006. 
0 Gráfico 1 demonstra o percentual de registros de estupro, lesão corporal e ameaça feitos nas DEAMs no período de 1999 a 2005. Como pode-se observar, em 2000, houve aumento dos percentuais referentes aos registros desses três delitos. Nos anos seguintes, nota-se uma leve queda com relação ao estupro e uma situação de estabilidade nos registros de ameaça e lesão corporal dolosa, sen- do que, no ano de 2005, para o delito de lesão corporal, o número de registros apresentou aumento considerável.

A Tabela 1 abaixo expõe os números de denúncias de estupro registrados no estado do Rio de Janeiro. De 2000 a 2005, são registrados um total de 17.622 casos.

Tabela 1 - Série histórica de atentado violento ao pudor e estupro no estado do Rio de Janeiro (valores absolutos e taxa anual por $\mathbf{1 0 0}$ mil habitantes)

\begin{tabular}{|c|c|c|c|c|c|c|c|c|c|c|c|c|c|c|}
\hline Ano & jan & fev & mar & $a b r$ & mai & jun & jul & ago & set & out & nov & dez & Total & $\begin{array}{l}\text { Taxa } \\
\text { Anual }\end{array}$ \\
\hline 1991 & 62 & 80 & 73 & 71 & 78 & 86 & 69 & 78 & 104 & 77 & 75 & 99 & 952 & 7,4 \\
\hline 1992 & 75 & 80 & 95 & 77 & 94 & 103 & 76 & 90 & 81 & 61 & 78 & 83 & 993 & 7,7 \\
\hline 1993 & 97 & 109 & 79 & 103 & 81 & 78 & 83 & 88 & 62 & 91 & 79 & 76 & 1.026 & 7,8 \\
\hline 1994 & 87 & 72 & 100 & 89 & 77 & 77 & 79 & 75 & 75 & 75 & 78 & 77 & 961 & 7,3 \\
\hline 1995 & 87 & 78 & 104 & 82 & 83 & 81 & 107 & 89 & 96 & 104 & 91 & 91 & 1.093 & 8,2 \\
\hline 1996 & 85 & 91 & 86 & 90 & 79 & 79 & 69 & 79 & 113 & 100 & 92 & 99 & 1.062 & 7,9 \\
\hline 1997 & 113 & 108 & 98 & 121 & 102 & 83 & 116 & 98 & 104 & 113 & 112 & 119 & 1.287 & 9,4 \\
\hline 1998 & 148 & 115 & 150 & 133 & 126 & 113 & 113 & 130 & 130 & 104 & 105 & 126 & 1.493 & 10,7 \\
\hline 1999 & 131 & 150 & 164 & 124 & 117 & 144 & 139 & 110 & 145 & 102 & 124 & 121 & 1.571 & 11,1 \\
\hline 2000 & 126 & 141 & 114 & 114 & 111 & 106 & 83 & 110 & 98 & 106 & 97 & 92 & 1.298 & 9,0 \\
\hline 2001 & 101 & 116 & 148 & 123 & 115 & 131 & 98 & 128 & 97 & 129 & 105 & 92 & 1.383 & 9,4 \\
\hline 2002 & 83 & 102 & 129 & 124 & 110 & 96 & 96 & 110 & 79 & 100 & 85 & 78 & 1.192 & 8,0 \\
\hline 2003 & 96 & 100 & 84 & 84 & 66 & 88 & 73 & 86 & 82 & 84 & 93 & 81 & 1.017 & 6,7 \\
\hline 2004 & 95 & 92 & 93 & 84 & 77 & 83 & 68 & 117 & 128 & 117 & 119 & 101 & 1.174 & 7,6 \\
\hline 2005 & 130 & 107 & 118 & 108 & 120 & 117 & 106 & 118 & 137 & 133 & 94 & 128 & 1.416 & 9,0 \\
\hline 2006 & 132 & 113 & 112 & 89 & 109 & 109 & 103 & 105 & 106 & 103 & 97 & 100 & 1.278 & 8,0 \\
\hline 2007 & 134 & 92 & 132 & 116 & 126 & 120 & 84 & 111 & 128 & 116 & 107 & 110 & 1.376 & 8,7 \\
\hline 2008 & 103 & 97 & 138 & 116 & 99 & 125 & 115 & 120 & 125 & 174 & 124 & 135 & 1.471 & 9,2 \\
\hline & & & & & & & & & & & \multicolumn{2}{|c|}{ Total Geral } & 22.043 & \\
\hline
\end{tabular}


Percebe-se que, após dois anos da publicação da Lei Maria da Penha, os números não param de aumentar. No entanto, é importante ressaltar que, em 2009, a nova redação dada ao artigo 213 do Código Penal enquadra o crime de atentado violento ao pudor como crime de estupro.

A partir do ano de 2009, em levantamento no Dossiê Mulher, os dados sobre o crime de estupro passaram a ser registrados junto com os dados do crime de atentado violento ao pudor ocorridos em 2008. Como pode ser observado na Tabela 2, o ano de 2008 registra 3846 denúncias de vítimas de estupro e atentado violento ao pudor no estado do Rio de Janeiro. Este número significa um aumento de $0,7 \%$ ou de 22 denúncias em relação ao ano de 2007 - levando em conta os dois tipos de crime -, representando uma média mensal de 320 denúncias de vítimas, alcançando a média 10.7 denúncias por dia. Para cada grupo de 100 mil habitantes, houve 24.3 mulheres que denunciaram que foram vítimas de estupro no ano de 2008 no estado.

Tabela 2 - Série histórica de atentado violento ao pudor e estupro no estado do Rio de Janeiro (valores absolutos e taxa anual por $\mathbf{1 0 0}$ mil habitantes)

\begin{tabular}{|c|c|c|c|c|c|c|c|c|c|c|c|c|c|c|}
\hline Ano & jan & fev & mar & $a b r$ & mai & jun & jul & ago & set & out & nov & dez & Total & $\begin{array}{l}\text { Taxa } \\
\text { Anual }\end{array}$ \\
\hline 2000 & 232 & 243 & 234 & 202 & 203 & 201 & 184 & 241 & 204 & 240 & 208 & 191 & 2.583 & 18,2 \\
\hline 2001 & 261 & 241 & 300 & 250 & 235 & 283 & 229 & 261 & 261 & 307 & 292 & 233 & 3.153 & 21,8 \\
\hline 2002 & 227 & 219 & 239 & 278 & 241 & 234 & 238 & 262 & 230 & 257 & 207 & 195 & 2.827 & 19,2 \\
\hline 2003 & 245 & 221 & 236 & 215 & 189 & 198 & 188 & 205 & 217 & 210 & 232 & 221 & 2.577 & 17,2 \\
\hline 2004 & 246 & 199 & 258 & 239 & 195 & 216 & 195 & 276 & 282 & 272 & 280 & 259 & 2.917 & 19,2 \\
\hline 2005 & 334 & 260 & 317 & 289 & 305 & 282 & 246 & 296 & 356 & 331 & 267 & 282 & 3.565 & 23,0 \\
\hline 2006 & 311 & 270 & 281 & 222 & 254 & 278 & 272 & 263 & 251 & 277 & 257 & 264 & 3.200 & 20,3 \\
\hline 2007 & 313 & 228 & 289 & 249 & 257 & 255 & 238 & 260 & 292 & 285 & 289 & 267 & 3.222 & 20,6 \\
\hline 2008 & 257 & 257 & 330 & 292 & 263 & 309 & 295 & 321 & 356 & 438 & 356 & 372 & 3.846 & 24,3 \\
\hline 2009 & 381 & 322 & 441 & 359 & 372 & 337 & 334 & 322 & 330 & 363 & 230 & 329 & 4.120 & 25,8 \\
\hline & & & & & & & & & & & \multicolumn{2}{|c|}{ Total Geral } & $32.0^{\circ}$ & \\
\hline
\end{tabular}


Em comparação a 2008, o ano de 2009 apresentou um aumento de 7,0. Em valores absolutos, foram mais 274 denúncias de vítimas de atentado violento ao pudor e estupro. A média mensal alcançou o número de 343 denúncias ou, ainda, uma média de 11.43 casos ao dia. 0 número total de casos, em 2009, foi de 4120.

A partir da versão de 2010, o Dossiê recebeu mudanças na forma de tratamento do crime de estupro para atender à nova tipificação estabelecida pela Lei $n^{0} .12 .015 / 09$, de 7 de agosto de 2009, em que também inclui o homem como sendo possível vítima.

Em relação a 2009, o ano de 2010 apresentou um aumento de 11,4\% ou, em valores absolutos, mais 469 denúncias de vítimas de estupro. A média mensal alcançou o número de 382 vítimas ou, ainda, uma mé dia de 12.73 vítimas ao dia, em um total anual de 4.589 casos.

Comparado a 2010, o ano de 2011 apresentou aumento de 6,1\% ou, em valores absolutos, mais 282 denúncias de vítimas de casos de estupro reportados. A média mensal alcançou o número de 406 registros ou, ainda, uma média de 12.18 casos ao dia e um total de 4.871 no ano.

0 Gráfico 2 demonstra que o percentual de denúncias de mulheres vítimas de estupro registrado em 2011 (82,6\%) corresponde ao maior já registrado desde 2006. Embora a Lei no 12.015/09 tenha ampliado o rol de denúncias das vítimas de estupro, incluindo os homens nesse universo, as mulheres permanecem como as principais vítimas de violência sexual, com maior número de denúncias. Mas éimportante ressaltar que os casos de denúncias que aumentaram não garantem que está havendo um aumento desse tipo de crime, pois, como mencionado anteriormente, são dados de casos denunciados. Isso se apresenta como uma conquista num mundo de tanta opressão, pois indica que as vítimas se sentem seguras para denunciar o agressor.

\section{Gráfico 2 - Vítimas de estupro no estado do Rio de Janeiro - 2006-2011 (Valores absolutos e diferenças percentuais)}

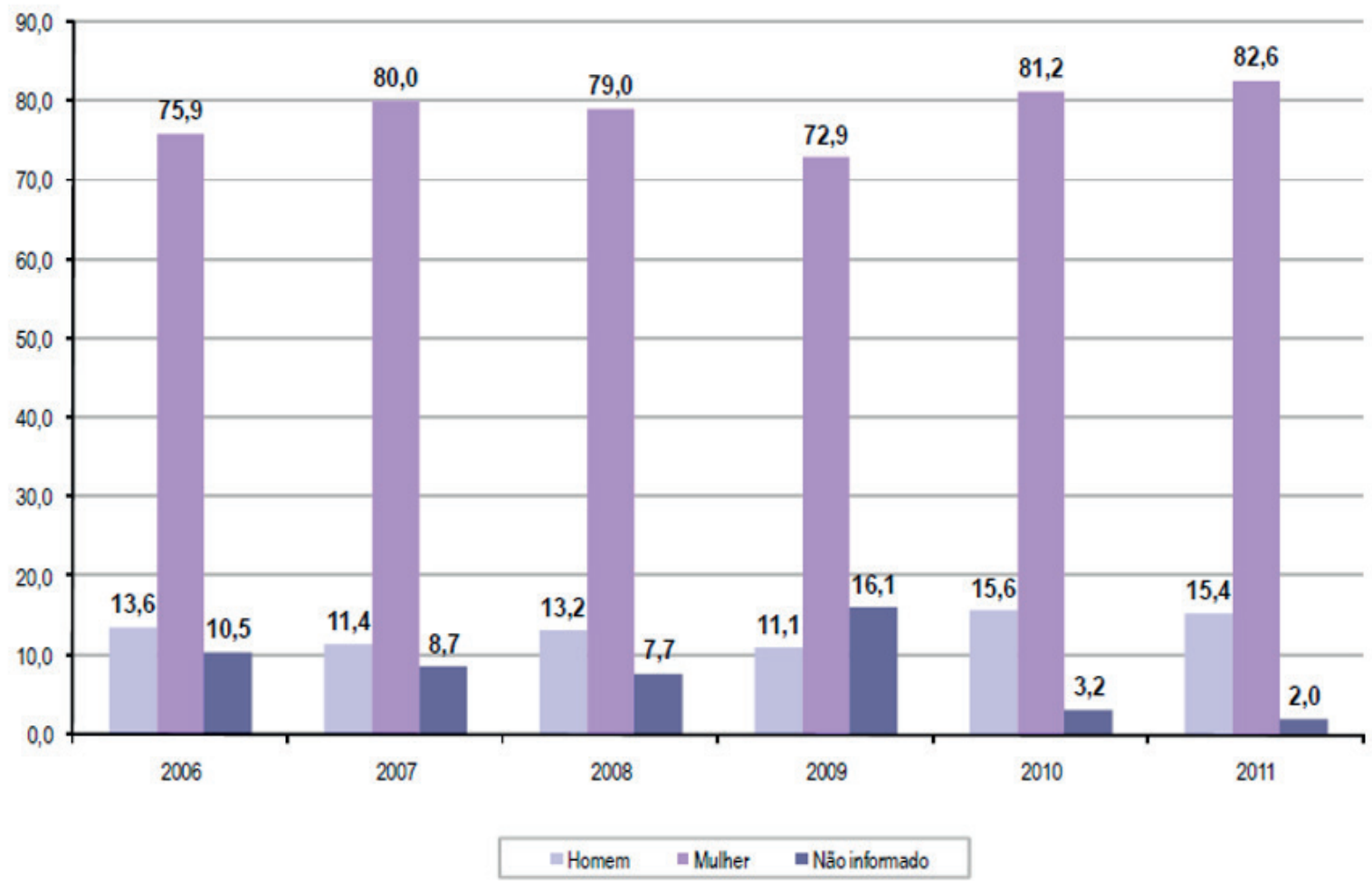

Fonte: Dossiê Mulher - Instituto de Segurança Pública - Governo do Estado do Rio de Janeiro, 2012. 
Em 2012, comparado a 2011, pode-se observar um aumento de $23,8 \%$ ou, em valores absolutos, uma adição de 1.158 casos registrados. A média mensal alcançou o número de 502 denúncias das vítimas ou, ainda, cerca de 16.74 vítimas ao dia, contabilizando quase 37 casos registrados de estupro para cada grupo de 100 mil habitantes. 0 total anual foi de 6.029 casos, conforme a Tabela 3 abaixo.

Tabela 3 - Série histórica de atentado violento ao pudor e estupro no estado do Rio de Janeiro (valores absolutos e taxa anual por $\mathbf{1 0 0}$ mil habitantes)

\begin{tabular}{|c|c|c|c|c|c|c|c|c|c|c|c|c|c|c|}
\hline Ano & jan & fev & mar & abr & mai & jun & jul & ago & set & out & nov & dez & Total & $\begin{array}{l}\text { Taxa } \\
\text { Anual }\end{array}$ \\
\hline 2008 & 257 & 257 & 330 & 292 & 263 & 309 & 295 & 321 & 356 & 438 & 356 & 372 & 3.846 & 24,6 \\
\hline 2009 & 381 & 322 & 441 & 359 & 372 & 337 & 334 & 322 & 330 & 363 & 230 & 329 & 4.120 & 26,1 \\
\hline 2010 & 345 & 391 & 341 & 337 & 345 & 347 & 402 & 402 & 402 & 359 & 442 & 476 & 4.589 & 28,7 \\
\hline 2011 & 396 & 416 & 434 & 389 & 417 & 395 & 365 & 423 & 448 & 404 & 380 & 404 & 4.871 & 30,1 \\
\hline \multirow[t]{2}{*}{2012} & 487 & 475 & 545 & 454 & 471 & 481 & 538 & 512 & 536 & 555 & 487 & 488 & 6.029 & 36,9 \\
\hline & & & & & & & & & & \multicolumn{3}{|c|}{ | Geral } & 23.455 & \\
\hline
\end{tabular}

Fonte: Dossiê Mulher - Instituto de Segurança Pública - Governo do Estado do Rio de Janeiro, 2013.

\section{A QUALIDADE DE ENSINO QUE VOCE JÁ CONHECE.}

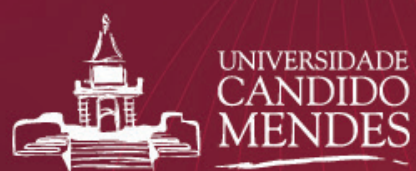

\section{INSCREVA-SE AGORA!}

口 PRESENCIAL

口 SEMIPRESENCIAL

口EAD 
Na versão do Dossiê Mulher 2013, foram feitas novas alterações: a revogação do artigo 214 do Código Penal, que definia o crime de atentado violento ao pudor, e a nova redação dada ao artigo 213 do Código Penal, que aborda o crime de estupro. Conforme atual redação do artigo 213, a conduta do crime, até então definida como atentado violento ao pudor, passou a compor a definição de estupro. A nova tipificação desse crime não distingue o gênero da vítima e inclui o homem também como vítima. Outro aspecto importante nessa lei é a inserção da tipificação "Estupro de vulnerável", por meio do artigo 217-A. No entanto, comparado a 2012, o ano de 2013 apresentou uma redução de $2,45 \%$ ou, em valores absolutos, menos 122 vítimas de estupro de ambos os sexos. A média mensal alcançou o número de 405 denúncias ou, ainda, cerca de 33.8 vítimas ao dia. Foram 57.7 denúncias para cada grupo de 100 mil habitantes. 0 total de 4871.

Na versão do Dossiê Mulher 2015, passaram a ser apresentado, de forma agrupada, os dados sobre os crimes sexuais, detalhando-os como crimes de estupro e tentativa de estupro. Ambos são incluídos como violência sexual, conforme a tipificação estabelecida pela Lei $n^{0}$ 12.015/09, de 7 de agosto de 2009.
Os dados de 2014, em relação a 2013, registraram uma redução de $3 \%$ ou menos 146 vítimas. Ainda assim, 0 estado do Rio de Janeiro registrou, em 2014, uma média diária de 13 denúncias de estupros, totalizando 4725. Do universo das vítimas de estupro registradas, 83,2\% eram do sexo feminino.

Já, em 2015, os crimes de violência sexual vieram separados em dois tipos: "estupro", com 4013 casos - em quem o total de vítimas mulheres corresponde a 84,5\% -; e "tentativa de estupro", com 387 casos. 0 somatório dos dois tipos de crimes totalizou 4.400 casos de denúncias.

Nos dados do ano de 2016, ficaram ainda mais detalhados os crimes de natureza sexual, abordando especificamente os crimes de estupro e de tentativa de estupro (Lei n ${ }^{0}$ 12.015/09, de 7 de agosto de 2009). Também foram incorporados, a partir da edição do Dossiê Mulher 2017, os delitos de assédio sexual (Lei n0 10.224, de 15 de maio de 2001) e importunação ofensiva ao pudor (Lei das Contravenções Penais).

\section{Tabela 6 - Mulheres vítimas de violência sexual no estado do Rio de Janeiro segundo delitos analisados de mulheres no estado do Rio de Janeiro - 2016-2017 (Valores absolutos e taxas por 100 mil mulheres)}

\begin{tabular}{|c|c|c|c|c|c|c|c|c|c|c|c|c|c|c|c|c|}
\hline Ano & jan & fev & mar & $a b r$ & mai & mai & jul & jul & ago & set & out & nov & dez & Total & Media & $\begin{array}{c}\text { Taxa } 100 \text { mil } \\
\text { mulheres }\end{array}$ \\
\hline 2012 & 392 & 403 & 429 & 348 & 380 & 380 & 448 & 448 & 436 & 459 & 456 & 447 & 403 & 4.993 & 416,1 & 59,5 \\
\hline 2013 & 414 & 420 & 413 & 451 & 377 & 377 & 390 & 390 & 380 & 429 & 458 & 395 & 351 & 4.871 & 405,9 & 57,7 \\
\hline 2014 & 475 & 463 & 381 & 389 & 362 & 362 & 372 & 372 & 377 & 406 & 397 & 387 & 360 & 4.725 & 393,8 & 55,7 \\
\hline 2015 & 402 & 309 & 377 & 350 & 291 & 291 & 355 & 355 & 374 & 328 & 329 & 338 & 342 & 4.128 & 344,0 & 48,4 \\
\hline 2016 & 351 & 285 & 323 & 366 & 313 & 313 & 332 & 332 & 331 & 363 & 348 & 338 & 353 & 4.013 & 334,4 & 46,1 \\
\hline
\end{tabular}

Total Geral 22.730

Fonte: Dossiê Mulher - Instituto de Segurança Pública - Governo do Estado do Rio de Janeiro, 2017. 
Tabela 5 - Mulheres vítimas de violência sexual no estado do Rio de Janeiro segundo delitos analisados de mulheres no estado do Rio de Janeiro - 2015-2016 (Valores absolutos, diferenças percentuais e taxas por 100 mil mulheres)

\begin{tabular}{|c|c|c|c|c|}
\hline & $\begin{array}{l}\mathrm{N}^{0} \text { de } \\
\text { mulheres } \\
\text { vítimas }\end{array}$ & $\begin{array}{l}\text { Diferença \% em } \\
\text { relação a } \\
2015\end{array}$ & $\begin{array}{l}\text { Taxa por } 100 \text { mil } \\
\text { mulheres } \\
\text { residentes }(2015)\end{array}$ & $\begin{array}{c}\text { Taxa por } 100 \text { mil } \\
\text { mulheres } \\
\text { residentes (2016) }\end{array}$ \\
\hline Estupro & 4.013 & $-2,8 \%$ & 48,4 & 46,1 \\
\hline Tentativa de estupro & 387 & $-20,0 \%$ & 5,7 & 4,4 \\
\hline Importunação ofensiva ao pudor & 588 & $-3,6 \%$ & 7,1 & 6,8 \\
\hline Assédio sexual & 126 & $-6,0 \%$ & 1,6 & 1,4 \\
\hline
\end{tabular}

Fonte: Dossiê Mulher - Instituto de Segurança Pública - Governo do Estado do Rio de Janeiro, 2017

Percebe-se uma redução em todos os tipos de crime de violência sexual em relação ao ano de 2015.

A versão do dossiê de 2017 trouxe um comparativo desde o ano de 2012 até o de 2016. Houve uma redução considerável nesse período.

Houve mais mudanças na versão 2018. Foi agrupado, na categoria de violência sexual, o delito ato obsceno, tipificado pelo artigo 233 do Código Penal Brasileiro como:
"[...] a prática de ato obsceno em lugar público, ou aberto ou exposto ao público". A violência sexual é o tipo de violência que mais atinge as mulheres proporcionalmente. No universo dos diferentes crimes sexuais aqui tratados, as mulheres representam entre $80 \%$ e $90 \%$ do total de vítimas. Em relação ao ano de 2016, em 2017, houve aumento nos casos reportados de crimes de estupro, de importunação ofensiva ao pudor, redução nos crimes de tentativa de estupro, ato obsceno e pequena redução nas denúncias do crime de assédio sexual, conforme mostra o Gráfico abaixo:

Tabela 6 - Mulheres vítimas de violência sexual no estado do Rio de Janeiro segundo delitos analisados. de mulheres no estado do Rio de Janeiro - 2016-2017 (Valores absolutos e taxas por 100 mil mulheres)

\begin{tabular}{|c|c|c|c|}
\hline & $\begin{array}{c}\mathrm{N}^{0} \text { de } \\
\text { mulheres } \\
\text { vítimas (2016) }\end{array}$ & $\begin{array}{c}\text { No de mulheres } \\
\text { vítimas } \\
(2017)\end{array}$ & $\begin{array}{c}\text { Taxa por } 100 \text { mil } \\
\text { mulheres residentes } \\
(2017)\end{array}$ \\
\hline Estupro & 4.013 & 4.173 & 47,7 \\
\hline Tentativa de estupro & 387 & 356 & 4,1 \\
\hline Assédio sexual & 126 & 125 & 1,4 \\
\hline Importunação ofensiva ao pudor & 588 & 595 & 6,8 \\
\hline Ato obsceno & 270 & 194 & 2,2 \\
\hline
\end{tabular}


Com relação a dados do ano de 2018, a versão do dossiê 2019 traz as seguintes informações em comparação com 0 ano de 2017: aumento das denúncias dos crimes de estupro, de assédio sexual e de importunação ofensiva ao pudor; redução de registros no crime de tentativa de estupro; e pequena redução no de ato obsceno, conforme mostra a Tabela 7:

Tabela 7 - Mulheres vítimas de violência sexual no estado do Rio de Janeiro segundo delitos analisados de mulheres no estado do Rio de Janeiro - 2017-2018 (Valores absolutos e taxas por 100 mil mulheres)

\begin{tabular}{|c|c|c|c|}
\hline & $\begin{array}{c}\mathrm{N}^{0} \text { de } \\
\text { mulheres } \\
\text { vítimas (2017) }\end{array}$ & $\begin{array}{c}\text { No de mulheres } \\
\text { vítimas } \\
(2018)\end{array}$ & $\begin{array}{c}\text { Taxa por } 100 \text { mil } \\
\text { mulheres residentes } \\
(2018)\end{array}$ \\
\hline Estupro & 4.173 & 4.543 & 50,6 \\
\hline Tentativa de estupro & 356 & 308 & 3,4 \\
\hline Assédio sexual & 125 & 150 & 1,7 \\
\hline Importunação ofensiva ao pudor & 595 & 638 & 7,1 \\
\hline Ato obsceno & 194 & 193 & 2,2 \\
\hline
\end{tabular}

A QUALIDADE DE ENSINO QUE VOCE JÁ CONHECE.

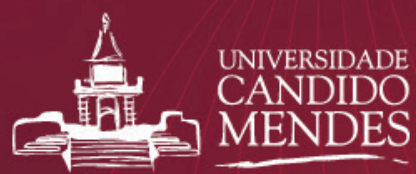

INSCREVA-SE AGORA!

口 PRESENCIAL

口 SEMIPRESENCIAL

口 EAD 
Nos dados do ano de 2019, as informações abrangematé o mês de julho conforme relatório por área do Instituto de Segurança Pública. Os números de denúncia dos delitos de estupro, de janeiro a julho, foram de 3.046, 0 que significa um aumento de $86(2,8 \%)$ denúncias com relação ao mesmo período de 2018, que teve 3.132 . Quanto aos anos de 2008 até julho de 2019, percebese uma redução gradativa, que começou em 2013 e se manteve até 0 ano de 2017, quando, a partir a partir de então, houve um aumento, o qual prevalece até hoje, com relação à média mensal por ano. Vale lembrar que o Decreto 8.086, de 30 de agosto de 2013, que institui o Programa Mulher: Viver sem Violência, alterado pelo Decreto 10.112, de 12 de novembro de 2019, para Programa Mulher Segura e Protegida, teve sua parcela de contribuição na alteração dos números de denúncias dos casos de violência sexual no ano de 2013:

No texto, fica instituído o Programa Mulher Segura e Protegida, com o objetivo de integrar e ampliar os serviços públicos existentes destinados às mulheres em situação de violência, por meio da articulação dos atendimentos especializados no âmbito da saúde, da justiça, da rede socioassistencial e da promoção da autonomia financeira, de acordo com o Art. $2^{\circ}$ do Decreto no 10.112, de 12 de novembro de 2019 (Brasil, 2019).

0 Gráfico 3 apresenta um comparativo do número de denúncias registradas ao longo dos anos de 2005 a 2018:

\section{Gráfico 3 - Número de denúncias de estupro por ano - estado do Rio de Janeiro}

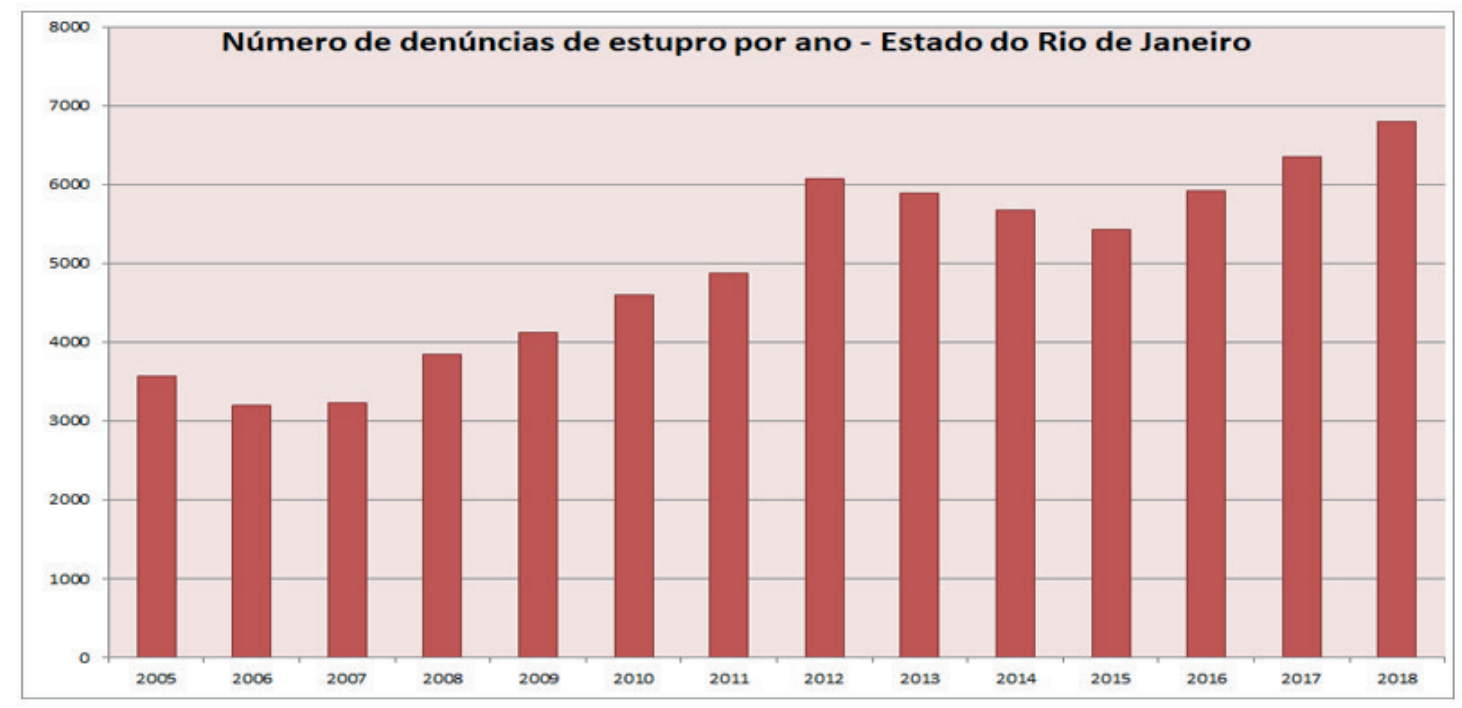

Fonte: Dossiê Mulher - Instituto de Segurança Pública - Governo do Estado do Rio de Janeiro, 2006 a 2019. Organizado pelos autores.

\section{A QUALIDADE DE ENSINO QUE VOCE JÁ GOWHECE.}

INSCREVA-SE AGORA!

口 PRESENCIAL

口 SEMIPRESENCIAL

口 EAD

www.ucam-campos.br

22 2726-2400 
Abaixo estão listadas as modificações ocorridas na descrição e no agrupamento do crime de estupro no decorrer dos anos:

2009 - Nova redação dada ao artigo 213 do Código Penal: atentado violento ao pudor enquadrado como crime de estupro

2010 - Lei $n^{0} .12 .015 / 09$, de 7 de agosto de 2009 inclusão de homens como vítimas

2012 - Artigo 217-A do Código Penal - inclusão de estupro de vulnerável

2014 - Edição do Dossiê Mulher 2015 - agrupamento de estupro e tentativa de estupro como crime de violência sexual

2016 - Edição do Dossiê Mulher 2017 - inclusão de assédio sexual e importunação ofensiva ao pudor como crime de violência sexual

2017- Artigo 233 do Código Penal Brasileiro - inclusão de ato obsceno como crime de violência sexual

\section{Considerações finais}

0 problema da violência contra a mulher, no Brasil e no mundo, vem ocorrendo, ao longo do tempo, em dimensões preocupantes - por certo, esse problema não é recente; ele se associa ao modelo de reprodução social fundado na desigualdade de gênero e no modelo patriarcal de sociedade. No entanto, os fatores contemporâneos se somam aos já enraizados.

0 número de casos de estupro registrados no estado do Rio de Janeiro, ao longo dos 13 anos de atuação da Lei Maria da Penha, apresenta-se, de certa forma, regular, porém não pode ser o único fator a ser considerado para a análise da eficácia da Lei. Os instrumentos de proteção às vítimas e a punição dos infratores também devem ser levados em conta, assim como das campanhas de conscientização.

Logo, é preciso estar atento ao fato de que o aumento das políticas e das campanhas de conscientização, além do alargamento dos parâmetros de classificação dos crimes, incentivam as denúncias, aumentando o número de casos registrados, a ponto de mascarar possíveis reduções reais no número de casos.

Essas mudanças no comportamento estão, de certa forma, associadas à segurança que as Delegacias de Atendimento Especializado à Mulher, os Núcleos de Atendimento à Mulher e a Lei Maria da Penha vêm proporcionando às vítimas, que se sentem amparadas para fazer a denúncia quando acometidas por esse tipo de violência. Dependendo do caso, já Ihes é concedida medida protetiva imediata.

Com isso, podemos concluir que há muito por se fazer, uma vez que as instituições criadas pelas políticas públicas para atender as vítimas no estado do Rio de Janeiro ainda não são suficientes para atender todos, por estarem mais concentradas nas capitais e nos grandes centros. Isso acaba por dificultar o atendimento às vítimas, que, em grande parte, pertencem às classes sociais mais baixas, tendo dificuldade de acessar as políticas públicas.

É impreterível que se busque tratar o problema nas suas múltiplas dimensões para que as políticas e as campanhas possam ser claras e efetivas. A (auto) conscientização é muito importante para que paradigmas sejam quebrados e, cada vez mais, direitos sejam conquistados. Com isso, torna-se indispensável que os movimentos e as lutas pelos direitos das mulheres e pelo combate à desigualdade de gênero, assim como a sociedade como um todo, tenham acesso ao conhecimento e às informações claras, para que os dados estatísticos possam ser interpretados de maneira adequada, gerando resultados positivos e efetivos no combate à violência contra a mulher. 
BANDEIRA, Lourdes Maria. Violência de gênero: a construção de um campo teórico e de investigação. 2014. Disponível em: http://www.scielo. br/scielo.php?script=sci_arttext\&pid=S0102-69922014000200008. Acesso em: 05 mar. 2020.

BELÉM DO PARÁ. Organização dos Estados Americanos, Convenção Interamericana para a Prevenção, Punição e Erradicação da Violência contra a Mulher ("Convenção de Belém do Pará"). 1994. Disponível em: http://www.unfpa.org.br/Arquivos/convencao_belem_do_para.pdf. Acesso em: 08 set. 2019.

BRASIL. Decreto n 8.086, de 30 de agosto de 2013. Disponível em: http://www.planalto.gov.br/ccivil_03/_ato2011-2014/2013/decreto/D8086. htm. Acesso em: 06 set. 2019.

BRASIL. Decreto n 10.112, de 12 de novembro de 2019. Disponível em: http://www.planalto.gov.br/ccivil_03/_Ato2019-022/2019/Decreto/ D10112.htm\#art2. Acesso em: 07 de mar. 2020.

BRASIL. Lei n 12.015, de 07 de agosto de 2009. Disponível em: http://www.planalto.gov.br/ccivil_03/_Ato2007-2010/2009/Lei/L12015.htm. Acesso em: 06 set. 2019.

BRASIL. Lei 11.340, de 07 ade agosto de 2006. Disponível em: http://www.planalto.gov.br/ccivil_03/_Ato2004-2006/2006/Lei/L11340.htm. Acesso em: 05 set. 2019.

BRASIL. Lei 13.827, de 13 de maio de 2019. Disponível em: http://www.planalto.gov.br/ccivil_03/_Ato2019-2022/2019/Lei/L13827.htm. Acesso em: 05 set. 2019.

BRASÍLIA, DF. Secretaria de Políticas para Mulheres/Ministério da Mulher, da Igualdade Racial e dos Direitos Humanos. Diretrizes para investigar, processar e julgar com perspectiva de gênero as mortes violentas de mulheres. 2016. Disponível em: http://www.onumulheres.org.br/ wp-content/uploads/2016/04/diretrizes_feminicidio_FINAL.pdf. Acesso em: 06 set. 2019.

BRASÍLIA, DF. Senado Federal, Subsecretaria de Biblioteca. Bibliografia sobre combate à violência contra a mulher. 2008. 116p. Disponível em: https://www2.senado.leg.br/bdsf/bitstream/handle/id/531486/000833298.pdf?sequence=1. Acesso em: 08 set. 2019.

BREDER, Robert Saner Lucas. A importância da Delegacia das Mulheres no combate a violência doméstica. 2018. Disponível em: https://www. direitonet.com.br/artigos/exibir/10761/A-importancia-da-Delegacia-das-Mulheres-no-combate-a-violencia-domestica. Acesso em: 03 mar. 2020.

CHAUI, Marilena. Ética e Violência no Brasil. Bio\&Thikos, São Paulo, v. 5, n. 4, 2011.

Dossiê Feminicídio. 0 que é feminicídio? Disponível em: https://dossies.agenciapatriciagalvao.org.br/feminicidio/capitulos/o-que-e-feminicidio/. Acesso em: 05 set. 2019.

GIL, Antonio Carlos. Como elaborar projetos de pesquisa. 5. ed. São Paulo: Atlas, 2010.

GUIMARAES, Maisa Campos; PEDROZA, Regina Lucia Sucupira. Violência contra a mulher: problematizando definições teóricas, filosóficas e jurídicas. Psicol. Soc., Belo Horizonte, v. 27, n. 2, p. 256-266, ago. 2015. Disponível em <http://www.scielo.br/scielo.php?script=sci_arttext\&pi$d=S 0102-71822015000200256 \&$ Ing=pt\&nrm=iso>. Acesso em: 08 set. 2019. DOI: http://dx.doi.org/10.1590/1807-03102015v27n2p256.

Instituto de Segurança Pública. Dossiê Mulher 2006 a 2019 - (ano base 2005 a 2018). Disponível em: http://www.isp.rj.gov.br/Conteudo. asp?ident=48. Acesso em: 05 set. 2019.

Instituto de Segurança Pública. Dados visualização - Principais Delitos - Relatório por área. Disponível em: http://www.ispvisualizacao.rj.gov. br/RelPorArea.html. Acesso em: 06 set. 2019.

ONU - Organização das Nações Unidas Brasil. CEPAL: 2,7 mil mulheres foram vítimas de feminicídio na América Latina e Caribe em 2017. Disponível em: https://nacoesunidas.org/cepal-27-mil-mulheres-foram-vitimas-de-feminicidio-na-america-latina-e-caribe-em-2017/. Acesso em: 09 mar. 2020.

POLÍCIA CIVIL. CGDEAM - Coordenadoria Geral das Delegacias Especializadas de Atendimento à Mulher. Disponível em: http://www.policiacivilrj.net.br/dpam.php. Acesso em: 03 mar. 2020.

PRADO, Débora. Culpabilização de vítima de feminicídio no Tribunal do Júri fere ética profissional e direitos humanos, afirma juíza. 2016. Disponível em: http://www.compromissoeatitude.org.br/culpabilizacao-de-vitima-de-feminicidio-no-tribunal-do-juri-fere-etica-profissional-e-direitos-humanos-afirma-juiza/. Acesso em: 09 mar. 2020.

SAFFIOTI, Heleieth lara Bongiovani. Gênero, patriarcado, violência. São Paulo: Fundação Perseu Abramo, 2004.

SAFFIOTI, Heleieth lara Bongiovani. 0 poder do macho. São Paulo: Moderna, 1987.

SOUZA, Renata Floriano de. Cultura do estupro: prática e incitação à violência sexual contra mulheres. Estudos Feministas, Florianópolis, v. 25, n. 1, p. 9-29, jan.-abr. 2017. Disponível em: http://www.scielo.br/pdf/ref/v25n1/1806-9584-ref-25-01-00009.pdf. Acesso em 05 mar de 2020. 